\title{
AQUí COMIENZAN TRES ROMANCES Y OTROS MUCHOS VILLANCICOS: POESÍA CASTELLANA EN UN PLIEGO IMPRESO EN CUENCA (1557)
}

\author{
Joan MAHIQUES CLIMENT \\ Universitat de Barcelona \\ Helena ROVIRA I CERDÀ \\ Universitat de Barcelona
}

\begin{abstract}
En): Several copies of eight chapbooks attributed to Juan de Cánova (about 15521558) are bound in a volume of the Biblioteca Comunale Augusta, Perugia, catalogued under the shelfmark [I L 1402]. In this paper we edit and contextualize fourteen poems printed in one of these chapbooks. Among all these compositions, the seven following are only known through this printed book: Señor Dios que me hiciste; Creo al tu poder divino; Venid, pecadores; Preguntaba la doncella; No sé si oís; Oh glorias al padre; Arrojé mi corazón.
\end{abstract}

Key words (En): Spanish sixteenth century; chapbook; editing; devotional poetry; contrafactum.

Resumen (Es): En un volumen de la Biblioteca Comunale Augusta de Perugia catalogado bajo la signatura [I L 1402] están encuadernados diferentes ejemplares de ocho pliegos sueltos atribuibles a la imprenta de Juan de Cánova hacia los años 1552-1558. En este artículo editamos y contextualizamos las catorce composiciones que transmite uno de estos pliegos, entre las cuales destacan las siguientes por ser conocidas a través de este impreso antiguo: Señor Dios que me hiciste; Creo al tu poder divino; Venid, pecadores; Preguntaba la doncella; No sé si oís; Oh glorias al padre; Arrojé mi corazón.

Palabras clave (Es): Siglo XVI; Pliegos sueltos; Edición; Poesía religiosa; Contrafacta poético-musicales.

\section{Introducción}

Son ocho en total las ediciones de pliegos sueltos del volumen [I L 1402] de la Biblioteca Comunale Augusta de Perugia que atribuimos al impresor Juan de Cánova: podría haberse estampado en Salamanca el más antiguo de los pliegos, datado en el año 1552, mientras las otras siete ediciones se publicaron en Cuenca hacia los años 1557-1558. ${ }^{1}$ Entre el grupo de pliegos conquenses, destacan dos de ellos por transmitir algunos poemas que, hasta donde hemos podido alcanzar en nuestra investigación, no son conocidos a través de ningún otro testimonio impreso o manuscrito. En este artículo estudiaremos y editaremos uno de estos dos pliegos, concretamente el que ocupa los fol. 28-31, numerados a mina de plomo, de la mencionada miscelánea perusina. Dicho ejemplar tiene el siguiente título:

AQVI COMIENCAN / tres Romances y otros muchos villan / cicos, sacados de la sagrada escriptura. El primero del / cielo salio vn archangel. El segundo de caluario salio el / demonio. El tercero que en los mas altos confines de aquel / precioso madero. Y vna obra a la sanctissima

\footnotetext{
${ }^{1}$ Abordamos el análisis de estos dos grupos de pliegos en MAHIQues; RoviRA (2013a; 2013b). El ejemplar que estudiaremos es atribuido al taller conquense de Juan de Cánova no solamente en el último trabajo mencionado sino también, anteriormente, por parte de INFANTES (2013), a quien debemos la primera descripción de todos los pliegos que constituyen el volumen [I L 1402]. El contenido de dicha colección también había sido presentado de manera más global y esquemática por el mismo INFANTES (2012). 
hostia. Y otra / al caliz. Agora nueuamente compuestos, y endereçados / al muy reuerendo señor Diego de Louera, $c a=$ / nonigo de salamanca mi señor. / Año .de. M.d.lvij.

En la tabla que presentamos a continuación asignaremos un número a cada una de las composiciones impresas en este pliego. Además, marcaremos en cursiva el íncipit de 3, 4, 9, 10, 11, 12 y 14, pues en estos casos concretos no hemos localizado ningún otro testimonio aparte del que transmite el pliego de Perugia. Retomando los datos expuestos en MAHIQUES y ROVIRA (2013b), señalaremos brevemente algunos aspectos sobre la difusión de las demás obras en el siglo XVI. En el Cancionero de Pedro del Pozo, probablemente del año 1547, nos han llegado copias de 5, 6, 7 y 8. ${ }^{2} \mathrm{Al}$ mismo tiempo, 5, 2 y 13 aparecen en un pliego de la Biblioteca Nacional de España [R/3661], mientras que Esteban G. de Nájera estampó 1, 2 y 5 en su Primera parte de la silva de romances (Zaragoza, 1550). ${ }^{3}$

\begin{tabular}{|l|l|}
\hline \multicolumn{1}{|c|}{ Obras por orden alfabético } & Orden de las obras en el pliego \\
\hline Adórote, Hostia bendita $\mathbf{7}$ & $\mathbf{1}$ Del cielo salió un arcángel \\
Adórote, sangre santa $\mathbf{8}$ & $\mathbf{2}$ Del Calvario salió el demonio \\
Arrojé mi corazón $\mathbf{1 4}$ & $\mathbf{3}$ Señor Dios que me hiciste \\
Creo al tu poder divino $\mathbf{4}$ & $\mathbf{4}$ Creo al tu poder divino \\
Del Calvario salió el demonio $\mathbf{2}$ & $\mathbf{5}$ En los más altos confines \\
Del cielo salió un arcángel $\mathbf{1}$ & $\mathbf{6}$ Si me parto, madre mía \\
En los más altos confines $\mathbf{5}$ & $\mathbf{7}$ Adórote, Hostia bendita \\
No sé si oís $\mathbf{1 1}$ & $\mathbf{8}$ Adórote, sangre santa \\
Oh glorias al padre $\mathbf{1 2}$ & $\mathbf{9}$ Venid, pecadores \\
Preguntaba la doncella $\mathbf{1 0}$ & $\mathbf{1 0}$ Preguntaba la doncella \\
Señor Dios que me hiciste $\mathbf{3}$ & $\mathbf{1 1}$ No sé si oús \\
Si me parto, madre mía $\mathbf{6}$ & $\mathbf{1 2}$ Oh glorias al padre \\
Venid, pecadores $\mathbf{9}$ & $\mathbf{1 3}$ Vi serrana de Belmar \\
Vi serrana de Belmar $\mathbf{1 3}$ & $\mathbf{1 4}$ Arrojé mi corazón \\
\hline
\end{tabular}

\section{Tendencias y modelos literarios}

La rúbrica inicial del pliego que estamos estudiando nos indica que los poemas que transmite son «sacados de la Sagrada Escritura», con lo cual se nos advierte ya desde el principio sobre el alcance temático de los mismos. En realidad, la mayor parte de las obras remiten de una manera u otra a la vida de Jesucristo, desde la

\footnotetext{
${ }^{2}$ Este manuscrito fue estudiado y en parte editado por RoDRíGUEZ-MoÑINO (1949-1950), y ahora forma parte del legado Rodríguez-Moñino-Brey de la Real Academia Española [RM 6952]. Por otra parte, 5 y 6, dos obras de Juan Tallante, fueron compiladas no solamente en el ms. 3880 de la Biblioteca Nacional de España, volumen del siglo XIX (JAURALDE Pou, 1998-2008 : II, 886-893), sino también en todas las ediciones quinientistas del Cancionero general de Hernando del Castillo y del Cancionero llamado guirlanda esmaltada de galanes de Juan Fernández de Costantina (RodRíGUEZ- MoÑINO, 1973 : I, 15-136, ítems 1-16).

${ }^{3}$ Véase un facsímil y una descripción de este pliego en Pliegos-Madrid (1957-1961 : IV, 241-244, ítem CLXI) y RodríGuez-MoÑINO (1997 : 770, ítem 1012). Parten de la silva zaragozana las reimpresiones barcelonesas de los años 1550 y 1552, la primera a cargo de Pedro Borín y la segunda a cargo de Jaume Cortey (RodRíGuEZ-MoÑINO, 1973 : I, 321-352, ítems 83, 84 y 85). Asimismo, 2 fue copiado en el ms. 961 de la Real Biblioteca (Zorita; DifRANCO; LABRADOR, 1991 : 186-188, ítem 58).
} 
anunciación del arcángel Gabriel a la Virgen María hasta la muerte de Cristo y su descenso a los infiernos. Concretando todavía un poco más, podríamos establecer las siguientes correspondencias:

Anunciación y Encarnación: 1 y $\mathbf{1 0}$

Natividad: 9, 11, 12 y 13

Pasión, descenso a los infiernos y Resurrección: $\mathbf{2}, 5$ y 6

Eucaristía: 3, 4, 7 y 8

Aunque el itinerario narrativo es fundamentalmente cristocéntrico, la figura de la Virgen María adquiere un gran protagonismo en casi todas las composiciones, si exceptuamos las de temática eucarística. Sin embargo, el último poema, que podría ser un añadido para completar el espacio que de otro modo podría haber quedado en blanco, es de carácter netamente profano, ya que 14 representa una situación de desamor en la que el yo poético, masculino, después de haber entregado su corazón a una casada, es rechazado por esta. Claro está que se trata de un motivo de la lírica tradicional, tal como muestra FRENK (2003 : II, 1338, ítem 1869bis).

La rúbrica inicial del pliego que estamos estudiando también nos pone sobre aviso respecto a las formas métricas más bien representadas, los romances y los villancicos. Al primer grupo pertenecen 1, 2 y 5. Mientras que este último romance inserta una lamentación a tres voces, declamada por la Virgen María, san Juan y santa Magdalena, los dos primeros introducen un sugestivo diálogo, inscribiéndose, además, dentro de la práctica literaria de los contrafacta, ya que vuelven a lo divino un romance bien conocido, tal como observaremos en seguida. Si en 1 tenemos como interlocutores al arcángel Gabriel y a la Virgen María, en 2 dialoga un demonio con Lucifer. Debe destacarse la gran habilidad con que, colocando estas dos obras una detrás de otra, se acentúa y al mismo tiempo se visibiliza el contraste entre ambas, poniendo de manifiesto no solamente las escenas culminantes de la historia de la salvación del linaje humano (desde la Encarnación hasta el descenso a los infiernos) sino también la pugna de dos huestes contrarias, la de Lucifer y la de Dios. Hay otro contrafactum del mismo romance vuelto a lo divino en el Cancionero de Nuestra Señora (Barcelona, Viuda de Hubert Gotart, 1591), cuyo inicio citaremos a continuación juntamente con el del modelo común de $\mathbf{1}$ y $\mathbf{2}$ : 
Aquí comienzan tres romances y otros muchos villancicos: poesía castellana en un pliego impreso

Dentro en Hierusalem
Christo muy humil salia
cauallero en carne humana
que muy bien le parecia
cartas lleua al padre Adam
de noble mensajeria
escriptas yuan con sangre
que de su cuerpo salia
el cuerpo que las lleuaua
treynta y tres años tenia.

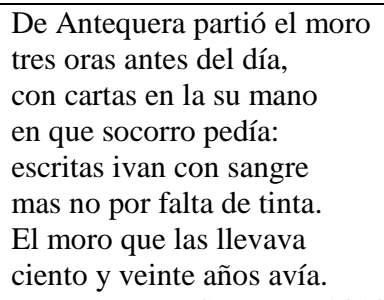

(Di STEFANO, $2010:$ 276, ítem 96)

(PÉREZ GóMEZ, $1952: 134)^{4}$

De 5 y 6 conocemos su autor, Juan Tallante, aunque el pliego de Perugia omite esta información. Se trata de un poeta cuya relación con la ciudad de Valencia puede constatarse a través de las ediciones más tempranas del Cancionero general. ${ }^{5}$ En relación con 6, quizás debería destacarse que, desde el punto de vista léxico-semántico, se reitera la contraposición parto/voy vs. volveréltornaré, conceptos que retomó la canción de amor medieval para expresar la ausencia de alguno de los amantes. A modo de ejemplo, podemos citar los siguientes versos atribuidos a Garci Sánchez de Badajoz:

Yo me parto y no me aparto,

y partiendo no me vo,

porque con vos quedo yo. (GALLAGHER, $1968: 76$, ítem 33$)^{6}$

Es verdad que 6 no utiliza el oxímoron y la paradoja como recursos expresivos, sino que simplemente pone en boca de Cristo unas palabras dirigidas a su madre, la Virgen María, donde se contraponen las ideas de la humillante ida y el glorioso regreso. Aún así, creemos que Juan Tallante podría haber retomado algunas expresiones de la lírica profana, unos recursos que, por cierto, también influyeron en el alba de carácter tradicional. Veámoslo en los siguientes versos del Cancionero musical de Palacio:

\author{
- Ya cantan los gallos \\ buen amor y vete \\ cata que amaneçe \\ - Que canten los gallos \\ yo como me iria \\ pues tengo en mis braços \\ la que yo mas queria (DutToN, 1990-1991 : II, 580, ID3617 «Vilches»)
}

\footnotetext{
${ }^{4}$ Citamos, según la edición que hemos tomado como referencia, la rúbrica que precede a este poema: «Romançe de la passion de nuestro señor Iesu Christo, al tono, De antequera sale el moro, de Antequera essa villa» (PÉREZ GómEZ, 1952 : 133).

${ }^{5}$ De la figura de Juan Tallante y su relación con el entorno literario valenciano se ha ocupado PEREARODRíGUEZ (2012 : 291-292). Este poeta tiene el privilegio de abrir el Cancionero general, impreso en Valencia en 1511 y 1514. Remitimos a la edición y las interesantes notas documentales, textuales y literarias sobre la vida y la obra de Juan Tallante en CASTILLO (2004 : I, 225-284, ítems 1-16).

${ }^{6}$ PÉREZ Bosch (2011 : 162-163 y 429-437, ítems III, V y VIII) publica y comenta otros poemas similares compuestos por el comendador Escrivá y compilados en el Cancionero general.
} 
Los poemas más breves que transmite el pliego que estamos estudiando son $\mathbf{3}$, 4, 7 y 8. Presentan todos ellos un esquema métrico similar, con versos octosílabos, rimas consonantes y una extensión que oscila entre los ocho y los diez versos. También coinciden en los temas que tratan, reiterando incluso las mismas rúbricas: 3 y 7 se refieren «A la Hostia», mientras que $\mathbf{4}$ y $\mathbf{8}$ aluden «Al Cáliz». El hecho de que las cuatro composiciones, tal como nos han llegado, sean una copla esparsa es un dato que no debe pasarnos por alto, pues las obras de este subgénero (frecuentemente vinculado a la proliferación de largos poemas alegóriconarrativos con inserciones líricas) solían responder no pocas veces a un proceso de fragmentación de composiciones más extensas. ${ }^{7}$ Si nos fijamos en $\mathbf{3}$, observamos que su inicio se asemeja sobremanera al de un poema de doña María Sarmiento (nuera del canciller Pero López de Ayala), cuyos únicos versos actualmente conocidos son los siguientes: ${ }^{8}$

Señor tu que me feziste

De nada muger entera

En la $V^{t a}$ se expresa la Autora:

Cordero que á pecadoras

Muchas has aconsolado

A esta, que todas oras

te quiso por Abogado,

Non le sea denegado

Contigo ayuntamiento

A Doña Maria Sarmiento

Que te ovo ofensado. (DutTon, 1990-1991 : II, 199, ID3674)

Los dos primeros versos citados nos hacen sospechar que $\mathbf{3}$ en realidad es una copla esparsa que deriva directamente del poema de doña María Sarmiento, aunque opera algunas adaptaciones de cierto relieve, sobre todo el cambio de un yo poético femenino por uno masculino. Desgraciadamente, al único testimonio conservado y conocido con la obra de doña María de Sarmiento le falta ya el tercer verso y los siguientes, hecho que nos impide establecer de manera concluyente qué relación existe entre este poema y 3 . $^{9}$

\footnotetext{
${ }^{7}$ Consideramos la esparsa como una estrofa única, suelta, independientemente de su métrica y estilo o de su autonomía o dependencia con respecto a un poema más extenso que lo precede en la transmisión textual. Para nosotros lo determinante es que la esparsa tenga o sea considerada per se como una obra poética autónoma individuable dentro de la fuente manuscrita o impresa que la transmite. Por eso no dudamos en llamar coplas esparsas a 3, 4, 7 y 8, aunque sus respectivos testimonios en ningún momento se refieran a ello. Discrepamos de los planteamientos y las conclusiones que señala Clavería (1989) en el único estudio que conocemos dedicado a la copla esparsa en la lírica castellana. Aunque sean más breves, las observaciones de PéREZ Bosch (2009 : 272-275) definen y contextualizan con mayor claridad este génere poético.

${ }^{8}$ A partir del actualmente perdido Cancionero de Fernán Martínez de Burgos, este fragmento fue copiado en el ms. 7329 de la Biblioteca Nacional de España de la mano de Rafael Floranes (17431801), con la siguiente rúbrica antepuesta: «Otras quando alzaren la ostia y el caliz y á los agnus. V octavas y media» (DuTTON, 1990-1991 : II, 199, ID3674).

${ }^{9}$ Es muy probable que el perdido Cancionero de Fernán Martínez de Burgos transmitiese alguna de las cuatro coplas esparsas del pliego que estamos estudiando, pues los fragmentos copiados en el ms. 7329 de la Biblioteca Nacional de España por el ya mencionado Rafael Floranes inciden en la temática eucarística. De otra composición hoy perdida solamente conocemos los dos primeros versos: «En forma de pan sincero / te adoro Iesu xpristto» (DUTTON, 1990-1991 : II, 198, ID3672).
} 
Aunque por lo menos en parte 3, 4, 7 y 8 parecen haber sido compuestas mucho antes, estas obras se inscriben dentro de la corriente de devoción eucarística que tanto relieve tuvo en el contexto de la segunda mitad del siglo XVI, coincidiendo con la difusión de una renovada espiritualidad católica surgida durante y después del Concilio de Trento (1545-1563) en contraposición a la reforma protestante. ${ }^{10}$

La cuarteta inicial de $\mathbf{9}$ debe relacionarse con la siguiente copla inserta en el Códice de autos viejos, pues ambas presentan una estructura métrica y unos giros verbales muy similares:

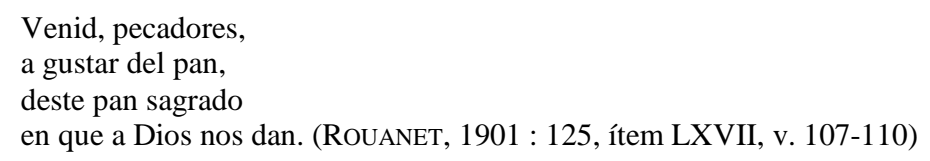

Además, tal como indica JAURALDE PoU (1998-2008 : IV, 2122-2124), en el ms. 5491 de la Biblioteca Nacional de España se transmite un villancico cuya primera copla coincide con el íncipit de 9. Dicho testimonio manuscrito, cuyo inicio transcribimos a continuación regularizando grafías, presenta algunos rasgos fonéticos que delatan su origen portugués y está compuesto por el estribillo más cuatro coplas. Aunque con diferente esquema de rimas, tiene una métrica similar a la de 9, con dos versos de vuelta que se repiten al final de cada estrofa:

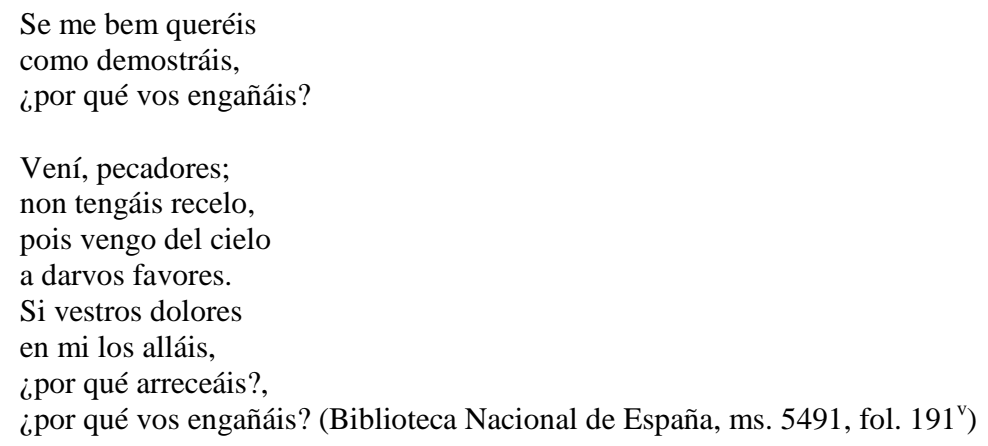

Si pasamos a 12, podemos observar que se trata de un Villancico al tono de «Para qué se afeita». FRENK (2003 : II, 1258, ítem 1746) aduce una buena diversidad de testimonios de este refrán, recogido, con una ligera variante, en el Teatro universal de proverbios de Sebastián de HOROZCO (2005: 482, ítem 2278). La perfecta casada de fray Luis de León recuerda el mismo adagio: ${ }^{11}$

No pregunta sin causa el cantarcillo común, ni es más castellano que verdadero: ¿Para qué se afeita la mujer casada? Y torna a la pregunta, y repite la tercera vez preguntando: ¿Para qué

\footnotetext{
${ }^{10}$ No son estas las únicas composiciones de la miscelánea de la Biblioteca Comunale de Perugia centradas en la temática eucarística, pues un pliego de esta colección transmite dos poemas de Joan Timoneda sobre el mismo asunto (MAHIQUES; ROVIRA, 2013c).

${ }^{11}$ Compárese el pasaje de fray Luis de León con la siguiente versión recopilada por MARTíneZ KLEISER (1953 : 456, ítem 39874): «¿Para quién se afeita la mujer casada, / si al marido sin afeites le agrada?».
} 
se afeita? Porque, si va a decir la verdad, la respuesta de aquel para qué es amor propio desordenadísimo. (LuIs De LEón, 1951 : 295)

Todavía hay otro estribillo que podría inspirarse en el mismo citado por fray Luis de León, a juzgar por las notabilísimas semejanzas que presentan ambos. Lo encontramos en una una pieza compilada por Gregorio Pesquera, la cual, por ser poco conocida, transcribimos íntegramente: ${ }^{12}$

\author{
¿Para qué comía la primera casada? \\ ¿Para qué comía, \\ para qué comía la fruta vedada? \\ La primera casada, \\ ella y su marido, \\ a Dios han traído \\ en pobre posada; \\ por haber comido \\ la primera casada, \\ por aver comido \\ la fruta vedada. \\ Vos fuistes primera \\ madre del pecado. \\ Ha Dios ordenado \\ que el cordero muera. \\ ¡Si nunca comiera \\ la primer casada! \\ ¿Para qué comía \\ la fruta vedada? (PESQUERA, 1554: $\operatorname{clxxxv}^{\mathrm{r}}-\mathrm{clxxxvi}^{\mathrm{V}}$ )
}

Aunque según la rúbrica precedente se identifica 13 como «Coplas», esta composición es una ensalada. Tal como indica INFANTES (2013 : 40, ítem 10), otro pliego de la colección de Perugia transmite una ensalada de romances que tuvo una gran difusión en el siglo XVI, la Glosa peregrina atribuida a Luis de Aranda. ${ }^{13}$ Este género poético y a la vez musical se caracteriza por intercalar, con su melodía específica, diversas canciones (por lo general de temática profana y de carácter tradicional) en un marco narrativo o alegórico que las más de las veces desarrolla un argumento religioso en virtud del cual las inserciones profanas cobran un nuevo

\footnotetext{
12 Aparte de regularizar grafías, corregimos una errata del último verso («futra»). Debemos la consulta de la Doctrina de Pesquera al Dr. Félix Santolaria Sierra. Del poema en cuestión hay una versión más conocida que la de Pesquera, pero fragmentaria, con unas consonancias en el estribillo que se amoldan aún más estrechamente al cantarcillo aducido en La perfecta casada: «¿Para qué comió / la primer casada, / para qué comió / la fruta vedada?» (FrENK, 2003 : 932, ítem 1393A). Esta versión fue interpolada en un auto titulado La caída de nuestros primeros padres, representado en México en 1539 según cuenta fray Toribio de Benavente en su Historia de los indios de la Nueva España. Existe también otra adaptación, seguramente llevada a cabo por Timoneda, ya que este autor la insertó en el Auto del Nacimiento (FRENK, 2003 : I, 932-933, ítem 1393B).

${ }^{13}$ Askins (1989 : 49-52) estudia la transmisión textual de esta obra, y da una relación de los versos encastados a lo largo de la Glosa peregrina. Véase, igualmente, RodRíGUEZ-MoÑINO (1997 : 153156, ítems 23-28), PiACENTINI (1984 : 1141-1146) y DíAZ-MAS (1993 : 233-245).
} 
significado sacro. ${ }^{14} \mathrm{Si}$ consultamos la edición de $\mathbf{1 3}$ que figura al final de este artículo, podemos observar que las citas primera y última derivan de una serranilla del marqués de Santillana:

Entre Torres y Canena,

açerca des' allozar,

fallé moça de Bedmar,

¡Sant Julián en buen estrena! (LóPEZ De MENDOZA, 1988: 9) ${ }^{15}$

Otros pasajes líricos insertos en $\mathbf{1 3}$ son el inicio del romance Paseábase el rey moro / por la ciudad de Granada, cuya difusión impresa en el siglo XVI ha sido estudiada por Di STEFANO (1992); y el de una obra con dos versiones copiadas en el Cancionero musical de Palacio. ${ }^{16}$ La notable difusión de otras tres canciones citadas en esta misma ensalada puede constatarse a través de los datos suministrados por FRENK (2003 : I, 417-419 y 476-477, ítems 602 y 697; II, 1329, ítem 1855):
¡Arded, coraçón, arded!, que no os puedo yo valer.
¿Qué me queréis, cavallero?
Casada soy, marido tengo.
El abad cayó de la puente súpitamente.

Por otra parte, los siguientes versos de Ambrosio Montesino podrían haberse inspirado en la canción inserta en los v. 19-21 de 13:

\author{
No la devemos dormir \\ la noche santa, \\ no la devemos dormir. (FrENK, 2003: I, 879, ítem 1290) ${ }^{17}$
}

\begin{abstract}
${ }^{14}$ En cierta medida, esta forma podría compararse con los poemas alegóricos con inserciones líricas de diversos autores, que tanta repercusión tuvieron en la poesía de cancionero. Aunque Gil Vicente ya había compuesto algunas ensaladas utilizando esta misma denominación, el primer gran compositor, del que nos ha llegado un corpus considerable, es Mateo Flecha el Viejo (1481-1553), estrechamente vinculado a la corte virreinal de Valencia. Ya en los primeros testimonios conocidos, este género manifiesta una cierta preferencia a representar la Natividad, tal como sucede en 13. Sobre las ensaladas a lo divino, remitimos a SÁNCHEZ MARTíneZ (1995 : I, 352-364), que las define bajo los siguientes términos: «Polimetría, poliglotismo y polifonía melódica» (p. 352). Los estudios más importantes sobre este género los debemos a PiACENTINI (1984), DíAZ-MAS (1993) y RoMEU I FIGUERAS (1999 : 34-53).

${ }^{15}$ Sobre la difusión de estos mismos versos en otras ensaladas o glosas de los Siglos de Oro, remitimos a DíAZ-MAS (1993 : 234).

${ }_{16}$ «Muchos van de amor heridos / y yo tabien / sin osar dezir de quien» (DutTon, 1990-1991 : II, 576, ID3965); «todos van de amor heridos / yo tambien / sin osar dezir de quien» (DutToN, 19901991 : II, 592, ID3965). Ambas versiones son comentadas por TOMASSETTI (2008 : 100).

${ }^{17}$ Tal como puede observarse en el corpus de Margit Frenk, este poema, aparte de ser impreso en el Cancionero de Ambrosio Montesino, nos ha llegado a través de otros dos testimonios fragmentarios con notación musical: el primero, impreso, en el Cancionero de Upsala (ejemplar impreso único de la Biblioteca Universitaria de dicha ciudad); el segundo, manuscrito, en el Cancionero de Gandía (Biblioteca de Catalunya, [M1967]). También podrían relacionarse con los respectivos estribillos de
\end{abstract}


El estudio literario de las obras impresas en el pliego poético que centra nuestra atención nos ha permitido trazar una serie de relaciones textuales entre diversos poemas o cantarcillos populares que sirvieron como modelo a numerosos poetas del siglo XVI. Asimismo, hemos observado cómo 3 tiene un inicio muy similar al de un poema de época medieval, escrito por doña María Sarmiento y conservado en un testimonio incompleto. Aunque esta semejanza plantea una serie de interrogantes irresolubles con los datos de que disponemos hoy en día, sí que parece señalar diversos aspectos: por una parte, la pervivencia de la tradición medieval durante el siglo XVI; por otra parte, la tendencia al fragmentarismo. Ambos elementos son fundamentales para entender los avatares de la transmisión textual de la lírica tradicional antigua y sus innumerables recreaciones que perviven a lo largo de la Edad Moderna.

\section{Criterios de edición}

Añadimos a continuación la edición del pliego estudiado, encuadernado en los fol. 28-31 de la miscelánea poética de la Biblioteca Comunale Augusta de Perugia [I L 1402]. Numeramos las composiciones y los versos de cada una de ellas. Del mismo modo, hemos restituido entre corchetes el estribillo o refrán de algunas estrofas cuando este se sobreentiende pero no se transcribe en el original. Marcamos en cursiva las inserciones de fragmentos de diversos cantarcillos en $\mathbf{1 3 .}$ Acentuamos, puntuamos y utilizamos las mayúsculas según los usos modernos. También regularizamos las correspondencias entre grafías y fonemas según la normativa actual, incluso simplificando algunos cultismos del original, como por ejemplo «escriptura» $\mathrm{y}$ «sanctissima», que hemos transcrito «Escritura» $\mathrm{y}$ «santísima». Sin embargo, en vocablos como «Agora», «recebido», «mesmo», «ansi» o «perficion», mantenemos en parte la lección del texto base, pues consideramos que las grafías traslucen rasgos fonéticos que divergen de los usos actuales más comunes. Asimismo, separamos amalgamas y resolvemos las abreviaturas. También añadimos algunas vocales protéticas o paragógicas para deshacer algunas elisiones que hoy en día no tienen representación gráfica. En algunos casos, para facilitar la lectura y la comprensión de las poesías editadas, hemos enmendado algunas lecciones de su testimonio base, que indicamos en nota. Como hemos omitido la referencia a la foliación manuscrita realizada sobre el original, que no tiene numeración impresa, marcamos los saltos de página y de columna a través de signos como $\left.\left.\right|^{1 \mathrm{ra}} \mathrm{o}\right|^{1 \mathrm{rb}}$. Cuando el texto ocupa toda la página, lo señalamos como en el siguiente ejemplo: $\left.\right|^{1 \mathrm{ra}-\mathrm{rb}}$. 


\section{BIBLIOGRAFÍA}

ASKINS Arthur Lee-Francis (1989), Pliegos Poéticos Españoles de la British Library, Londres (Impresos antes de 1601). Edición en facsímile precedida de una presentación y notas bibliográficas por Arthur Lee-Francis Askins, Madrid, Joyas Bibliográficas, vol. 1 [Presentación y notas bibliográficas].

CASTILlo Hernando del (2004), Cancionero general, (ed. Joaquín GonZÁlez CUENCA), 5 vol., Madrid, Castalia.

Clavería Carlos (1989), Modesta contribución a la lírica española. Cuatro notas sobre la 'copla esparza', Anthropos. Revista de documentación científica de la cultura, suplemento 12 [Martín de Riquer. Antología: Cantares de gesta, trovadores, narrativa medieval, literatura catalana y castellana, y vida caballeresca], p. 186-195.

Di STEFANO Giuseppe (1992), Los textos del 'Romance del rey moro que perdió Alhama' en las fuentes del siglo XVI, Estudios de Folklore y Literatura dedicados a Mercedes Díaz Roig (ed. Beatriz GARZA CuARón y Yvette JiMÉnEZ DE BÁEZ), México, El Colegio de México, p. 41-51.

Di STEFANO Giuseppe ed. (2010), Romancero, Madrid, Castalia.

DÍAZ-MAS Paloma (1993), Algo más sobre romances (y canciones) en ensaladas, Nueva Revista de Filología Hispánica, 41, p. 231-250.

DutToN Brian (1990-1991), El cancionero del siglo XV, c. 1360-1520 (Cancioneros musicales al cuidado de Jineen KROGSTAD), 7 vol., Salamanca, Universidad de Salamanca.

Frenk Margit (2003), Nuevo Corpus de la Antigua Lírica Popular Hispánica (siglos XV a XVII), 2 vol., México, Universidad Nacional Autónoma de México / Colegio de México / Fondo de Cultura Económica.

Gallagher Patrick (1968), The Life and Works of Garci Sanchez de Badajoz, London, Tamesis Books.

Horozco Sebastián de (2005), Teatro universal de proverbios (ed. José Luis AlONSO HERNÁNDEZ), Salamanca, Universidad de Salamanca.

INFANTES Víctor (2012), Nuevas de poesía áurea. Cuarenta y dos pliegos poéticos desconocidos del siglo XVI, más dos en prosa, Hibris. Revista de Bibliofilia, 67-68, p. 39-45.

INFANTES Víctor (2013), Una cuarentena poética desconocida. Los pliegos sueltos del siglo XVI de la Biblioteca Comunale Augusta de Perugia, Criticón, 117, p. 29-63.

JAURALDE POU Pablo (dir.) (1998-2008), Catálogo de manuscritos de la Biblioteca Nacional con poesía en castellano de los siglos XVI y XVII, 7 vol., Madrid, Arco Libros.

López De MENDOZA Ínigo (Marqués de Santillana) (1988), Obras completas (ed. Ángel Gómez MoRENO y Maximilian P. A. KERKHOF), Barcelona, Planeta.

LUIS DE LEÓN (Fray) (1951), Obras completas castellanas (ed. Félix GARCíA), Madrid, Editorial Católica.

MAHIQUeS Climent Joan; RoviRA I CERDÀ Helena (2013a), Un pliego poético atribuible a Juan de Cánova y un plagio de Bartomeu Auledes, Artifara. Revista 
Aquí comienzan tres romances y otros muchos villancicos: poesía castellana en un pliego impreso

de lenguas y literaturas ibéricas e hispanoamericanas, $13, \quad$ p. $3-18$. http://www.ojs.unito.it/index.php/artifara/article/view/277

MAHIQUes Climent Joan; RoviRA I CERDÀ Helena (2013b), Siete pliegos impresos en Cuenca por Juan de Cánova, Studia Aurea. Revista de Literatura Española y Teoría Literaria del Renacimiento y Siglo de Oro, 7, p. 417-444. http://studiaurea.com/article/view/v7-mahiques

MAHIQUes Climent Joan; RoviRA I CERDÀ Helena (2013c), Dos plecs poètics amb obres de Joan Timoneda i Andreu Martí Pineda, Els marges. Revista de Llengua i Literatura, 101, p. 82-104.

MARTÍNEZ KLEISER Luis (1953), Refranero general ideológico español, Madrid, Real Academia Española.

PÉREZ GóMEZ Antonio (1952), Cancionero de nuestra Señora en el qual ay muy buenos romances, canciones y villancicos (1591), Valencia, Castalia.

PÉREZ BosCH Estela (2009), Los valencianos del 'Cancionero general': estudio de sus poesías, Valencia, Universitat de València.

PÉREZ BOSCH Estela (2011), Los poetas valencianos del 'Cancionero general' (Valencia, 1511 y 1514), Valencia, Institució Alfons el Magnànim.

PEREA-RodRÍGUEZ Óscar (2012), 'Night Moves': Nocturnality within Religious and Humanist Poetry in Hernando del Castillo's 'Cancionero general', eHumanista. Journal of Iberian Studies, 22, p. 289-329. http://www.ehumanista.ucsb.edu/volumes/volume_22/index.shtml

PESQUERA Gregorio de (1554), Doctrina christiana, y Espejo de bien biuir: diuidido en tres partes. La primera es vn dialogo ó coloquio entre dos niños con muchas cosas de la fe prouechosas, y la doctrina declarada y luego la llana. En la segunda se contienen muchas obras breues y de buena y sana doctrina. La tercera tiene muchas coplas y cantares deuotos para se holgar y cantar los ninos, Valladolid, Sebastián Martínez.

PiACENTINI Giuliana (1984), Romances en 'ensaladas' y géneros afines, El crotalón. Anuario de Filología Española, 1, p. 1135-1173.

Pliegos-Madrid (1957-1961) = Pliegos Poéticos Góticos de la Biblioteca Nacional, 6 vol., Madrid, Joyas Bibliográficas.

RoDRÍGUEZ-MoÑINO Antonio (1949-1950), El cancionero manuscrito de Pedro del Pozo (1547), Boletín de la Real Academia Española, 29, p. 453-509; 30, p. 123-146 y 263-312.

RODRÍGUEZ-MOÑINO Antonio (1973), Manual bibliográfico de cancioneros y romanceros impresos durante el siglo XVI (coord. Arthur L.-F. AsKINS), 2 vol., Madrid, Castalia.

RODRÍGUEZ-MOÑINO Antonio (1997), Nuevo diccionario bibliográfico de pliegos sueltos poéticos (siglo XVI) (edición corregida y actualizada por Arthur L.-F. ASKINS y Víctor INFANTES), Madrid, Castalia.

ROMEU I FIGUERAS Josep (1999), Assaigs de literatura valenciana del Renaixement, Alacant, Universitat d'Alacant / Institut Interuniversitari de Filologia Valenciana.

RouAnet Léo (ed., 1901), Coleccion de Autos, Farsas y Coloquios del siglo XVI. Tome III, Barcelona / Madrid, L’Avenç / M. Murillo. 
Aquí comienzan tres romances y otros muchos villancicos: poesía castellana en un pliego impreso SÁNCHEZ MARTíneZ Francisco Javier (1995), Técnicas de divinización de textos líricos y otros fundamentos teóricos. Tomo I, Murcia, F.J. Sánchez Martínez Editor.

TOMASSETTI Isabella (2008), 'Mil cosas tiene el amor'. El villancico cortés entre Edad Media y Renacimiento, Kassel, Reichenberger.

ZoritA C. Ángel; DifrANCo Ralph A.; LABRADOR HERRAIZ José J. (eds.) (1991), Poesías del maestro León y de fr. Melchor de la Serna y otros (siglo XVI). Códice número 961 de la Biblioteca Real de Madrid, Cleveland, Cleveland State University. 

Sagrada Escritura: el primero, «Del cielo salió un arcángel»; el segundo, «De Calvario salió el demonio»; el tercero, ${ }^{18}$ "En los más altos confines / de aquel precioso madero»; y una obra a la santísima Hostia y otra al Cáliz. Agora nuevamente compuestos y enderezados al muy reverendo señor Diego de Lovera, canónigo de Salamanca, mi señor. Año de MDLVII. $\left.\right|^{1 \text { va }}$

Del cielo salió un arcángel de entre la gran monarquía con cartas del rey del cielo para la Virgen María, en su pura mente escritas, que no de papel ni tinta. El nuncio que las llevaba Gabriel por nombre había. El caballo lleva tal que gran parte relucía. $\mathrm{Su}$ figura reverbera, que espanto a todos ponía. Blanca estola en el su cuello, de castidad guarnecida, con santas alas se mueve, que caballo no quería. Por los campos de Betania volaba, que no corría. Del espíritu encendido de la su boca, decía:

- Si supieses, Virgen sacra, mi dulce mensajería, en tus sagrados cabellos corona se esculpiría como aquella que por reina de los cielos se escogía.La Virgen, en esto estando, en resplandor se encendía; y el mensajero llegado estas palabras decía:

-Dominus tecum, Señora, ave gloriosa María, | ${ }^{\text {1vb }}$ sábete que eres por madre del que te crió escogida. Bendito será aquel fruto

que en tu vientre te esculpía. Buen Jesús de Nazareno

\footnotetext{
${ }^{18}$ tercero] tercero que
} 
por nombre el Verbo tenía.

- Sea hecho, sacro ángel, según tu mensajería.-

Estas palabras diciendo, el Verbo encarnado había.

Las rodillas por el suelo, el nuncio se despedía para tornar a la gloria con extremada alegría. Recebido es en el cielo con música y armonía.

Romance que dice: «Del Calvario salió el demonio»

Del Calvario salió el demonio,

del Calvario ya salía.

Cartas llevaba en su mano, cartas de mensajería; escritas iban con sangre que Cristo vertido había. El demonio que las lleva ciento y veinte ansias hacía, ciento y veinte hace el demonio y a sí mesmo maldecía.

La barba lleva abrasada y en la calva pez ardía. Caballero en una sierpe que volaba y no corría $\left.\right|^{\text {ra }}$ y en la mano una víbora, y también le parecía, a las puertas del infierno a grandes voces decía: - Si supieses, Lucifer, mi triste mensajería, mesarías tus cabellos, tus barbas arrancarías.

—Dígasmelas tú, el demonio, si no yo reventaría.

-Ten paciencia, Lucifer, que yo te las contaría.

Allá en el monte Calvario han muerto al santo Mesías. Tras mí viene en los alcances; muy presto me alcanzaría.-

Manda cerrar las puertas

cuantas en el infierno había. 
Las puertas están cerradas.

Cristo llegado había.

«Atollite portas», dice.

Ninguno le respondía.

Todas las puertas se abren, de par en par se abrían.

Sacará Adán y a Eva

con toda su compañía,

sacará los Santos Padres

cuantos en el limbo había:

a la diestra de Dios Padre, allí sentar los hacía.

[3]

A la Hostia

Señor Dios que me heciste de nada varón entero $\left.\right|^{\text {rb }}$ $\mathrm{y}$, después, en el madero de la cruz me redemiste, pues te place y lo quesiste

en forma de pan ser visto, adórote, Jesucristo, pues de la Virgen naciste.

[4]

Creo al tu poder divino

Al Cáliz

ser asaz posible cosa

tornar en sangre preciosa

el agua vuelta con vino.

Hijo de Dios uno y trino,

Jesús, mi redemidor,

adórote yo, Señor;

a solos tus pies me inclino.

[5]

Romance de la sagrada Pasión

En los más altos confines

de aquel precioso madero,

padecía el soberano

culpas del padre primero,

do fueron todas lavadas

en la sangre del cordero, presente la triste madre

hasta lo más postrimero, y el que fue dado por hijo 
a cambio del heredero,

10

y $\mathrm{la}^{19}$ que fue perdonada

de Jesús tan de ligero.

Los clamores que explicaban

aplacan el día tercero; $\left.\right|^{2 \mathrm{va}}$

las palabras eran tales

cuales aquí las refiero:

-Oh piadosa virtud,

Hijo de Dios verdadero,

todo vos veo trocado

en aspecto de extranjero:

vuestro bulto glorioso

no aquel cual de primero

ni el color rubicundo,

fulgor de lustre de acero;

de pinturas sanguinosas

ocupado todo el cuero;

vuestros sacros pies y manos

puestos en clavos de acero;

en vuestra santa cabeza,

guirnalda de noble suero

con sesenta y dos merletes, ${ }^{20}$

no de flores de rosero,

mas de agujas inventadas

de algún cruel carnicero.-

Los arroyos de la sangre

arroyaban el terrero

do la santa cruz estaba

acuñada en el otero.

En estas penalidades

expiró el Mesías vero,

y ansí quisiera la madre

por llevar tal ${ }^{21}$ compañero

si no por el esperanza

y fe del día tercero.

Fin

[6]

Villancicos por desecha

Si me parto, madre mía,

voyme a Dios. $\left.\right|^{2 v b}$

Luego volveré yo a vos.

\footnotetext{
${ }^{19}$ la] a la

${ }^{20}$ merletes] merletos

${ }^{21}$ tal] el
} 
Pártome todo llagado, oprimido y denostado.

Tornaré glorificado en días dos.

Luego volveré yo a vos.

Voy a los de la prisión

que libré por mi Pasión,

que reciban bendición

allá con nos.

Luego volveré yo a vos.

A los cuales redemí

con los tragos que bebí.

No fueron de menjuí

ni de agua-ros.

Luego volveré yo a vos.

Eran de tal amargura

cual designa la Escritura,

por ejemplo y por figura,

san Ambrós.

Luego volveré yo a vos.

Deo gratias

Adórote, Hostia bendita,

A la Hostia

bajo de cuya figura

está la persona pura,

humanada criatura

de perfición infinita, $\left.\right|^{\text {ra }}$

dulce y muy manso cordero,

rey eterno y consagrado

tal cual tú, Dios verdadero,

veniste a ser encarnado.

Adórote, sangre santa

en ese cáliz metida,

aquella que nos dio vida

cuando fue toda vertida ${ }^{22}$

desde el cabello a la planta.

${ }^{22}$ vertida] metida \|| Nuestra enmienda se corresponde a la lección del texto editado por RoDRíGUEZMoÑINO (1949-1950 : 302). 
Creo sin revés ninguno,

ciertamente, sin recelo,

que de ambos a dos consuno

sois aquel Dios trino y uno

que vive y reina en el cielo.

Venid, pecadores,

Sotica

$\mathrm{y}$ ved vuestro bien,

que una Virgen sacra

lo parió en Belén.

Cesen profecías

cuantas son y han sido

de nuestro Mesías:

ya hoy es nacido.

Y su nombre ha sido

Jesús Nazarén,

que una [Virgen sacra

lo parió en Belén].

De Virgen y Señora

tomó carne humana,

como el sol que pasa $\left.\right|^{3 \mathrm{rb}}$

por la vidriera.

Y ansí Él naciera

por mejor convén,

que una [Virgen sacra

lo parió en Belén].

De Virgen y madre

nació, si miramos.

Lucifer no ladre,

que, si bien notamos,

¿por qué nos sudamos?

Bajó nuestro bien,

que una [Virgen sacra

lo parió en Belén].

Albricias demando,

que agora nació.

Él está llorando

lo que Adán pecó.

Por ello le dio

el Padre en rehén, 
que una [Virgen sacra

35

lo parió en Belén].

Por ser buen pastor

se nos ha mostrado.

Ve qué gran dolor,

sin igual hallado,

que haya Adán pecado

y a Él pena den;

que una [Virgen sacra

lo parió en Belén].

Culpa sin desculpa

fue la tuya, Adán.

Tienes tú la culpa

y Él pasa el afán.

Los que contigo están

se gocen también,

que una Virgen sacra

lo parió en Belén. | $\left.\right|^{\text {va }}$

Preguntaba la doncella

a san Gabriel:

—Di, resplandeciente estrella, ¿cómo puede aquesto ser?-

Preguntaba muy turbada

la Virgen, reina del cielo, temerosa y con recelo

de esta tan alta embajada.

Fuele por respuesta dada

que Dios la quiso escoger.

¿Cómo puede aquesto ser?

Hecha la salutación,

— ¿Madre de Dios yo llamada?

— respondió nuestra abogada-.

Nunca conocí varón.

Por tanto, con afición, ya deseo de saber...

¿cómo puede aquesto ser?-

Ya después que hobo entendido

la Virgen tal embajada, 
cuando se vio consagrada

del cordero concebido,

viendo a su Dios escondido

en una pobre mujer,

preguntaba la doncella:

[-Di, resplandeciente estrella,

¿cómo puede aquesto ser?-]

Cuando en aquesto vacila

la reina muy soberana, respondió de buena gana:

-Ecce Domini ancilla-, aquella que la sibila

solía dar a entender.

¿Cómo puede aquesto ser? $\left.\right|^{3 \mathrm{vb}}$

Gócese cualquier nación

que es con fe alumbrada, pues que de esta embajada resultó su redención.

$\mathrm{La}^{23}$ Virgen con afición

a Aquel quiso nacer

por tan libres nos hacer.

No sé si oís

llorar nuestro Dios, madre de Él y nos.

Mirad cómo llora

por vos en el heno

quien bajó, Señora,

del paternal seno

por pecado ajeno.

Halagalde vos,

madre de Él y nos.

Vida de la vida

de nuestro consuelo,

Virgen y parida

del Señor del cielo,

doleos de su duelo,

pues lloró por vos,

madre de Él y nos.

${ }^{23} \mathrm{La}$ a a la 
Llave de David, sacra piedra y mar, flor de estirpe y vid que fue Abraham, consuelo de Adán, consolad mi Dios, madre de Él y nos. $\left.\right|^{\text {ra }}$

Al Dios del poder,

Virgen, concebistes.

Do dio a vos ser, vos carne le distes $\mathrm{y}$ virgen paristes humanado a Dios, madre de Él y nos.

Divinal señuelo de fuerte ${ }^{24}$ victoria, que puso en el suelo el rey de la gloria, tened en memoria que sola sois vos madre de Él y nos.

Morada de fe, templo virginal

que escogida fue para el celestial, pues llora el gran mal de los padres dos, acallaldo vos, madre de Él y nos.

Fin

Oh glorias al Padre y al Hijo también, pues nació en Belén de Virgen y madre.

Por nos redemir,

el rey soberano

quiso acá venir $\left.\right|^{4 \mathrm{rb}}$

${ }^{24}$ fuerte] fuente 
a hacerse humano

y escogió de mano

la Virgen por madre.

Oh glorias al Padre

y al Hijo también,

pues nació en Belén

de Virgen y Madre.

Vi serrana ${ }^{26}$ de Belmar.

¡San Julián de buena estrena!

Es la gentil serrana

la madre del Niño Dios,

que fue siempre entre Él y nos

medianera soberana.

Cantemos de buena gana

al Niño tan excelente:

El abad cayó de la puente,

súbitamente.

Hoy el demonio cayó

de su mando y señorío.

Quebrantado ha ya su brío

este Niño que nació.

Pues tan buen gozo nos dio,

este cantar decir quiero:

¿Que me queréis, el caballero?

Casada soy, marido tengo.

Que no la puedo dormir,

la noche amores;

que no la puedo dormir.

En la noche del pecado, ninguno puede dormir.

$\mathrm{Si}$ a Jesús veo venir, $\left.\right|^{4 \mathrm{va}}$

tiene por encomendado.

Quien a Él no está abrazado

cuéntese con los perdidos.

Todos van de amor heridos, 
y yo también,

sin saber decir de quién.

De amor vienen heridos

cuantos hoy van a Belén, viendo todo nuestro bien envuelto en paños rompidos.

Pues de Él somos redemidos,

cantaremos con placer:

Arded, corazón, arded, pues que no os puedo yo valer.

Cúmplete, mi corazón, arder siempre en vivas llamas

de Jesú, que si le amas ternás gran consolación. Su muy preciosa Pasión ten siempre por tu tesoro: Paseábase el rey moro por la ciudad de Granada.

Nuevas que le han venido cómo Alhama era ganada. — ¡Ay, mi Alhama!-

Bien te puedes pasear, perro moro, Lucifer, pues fenece tu poder y tu soberbio reinar; que el Niño Dios te ha de atar con muy penosa cadena $\left.\right|^{4 \mathrm{vb}}$ entre Torres y Jimena, saliendo de un allozar.

Arrojé mi corazón

a una casada, y tomó la posesión sin dejar nada.

Vila estar a una ventana.

Yo, en viendo, la fe le di

y arrojelo tan de gana

que luego sin él me vi y ella muy abrasada.

Y tomó la posesión 
sin dejar nada.

Como la vi tan hermosa, cebeme yo tanto de ella que solamente de vella no puedo hacer otra cosa.

Mas ella, como raposa, se entregó como malvada y tomó la posesión sin dejar nada.

Viéndome sin él, cuitado, bien pensé hallalle ansí. —Doleos del desdichado, pues que el corazón perdí.Dijo: - ¿Qué se me da a mi? De ello no se me da nada.-

Y tomó la posesión, sin dejar nada.

Deo gratias 